\title{
Emerging breast cancer epidemic: impact on palliative care
}

\author{
Anne Merriman*
}

\section{Introduction}

Imagine that you are poor and living in Africa, you develop breast cancer, your country has no oncology service, no prevention, early detection or treatment, and the strongest analgesic is paracetamol. You are lucky just to be found under these circumstances.

This is the plight of thousands of women and some men in Africa today. And yet to control their pain and symptoms and bring them to peace before the end of life would cost so little.

The West today sees the breast as a fashion symbol. In my lifetime it has gone from needing to be hidden from all to being flaunted, pumped up and pumped down according to fashion. A treatise could be written on fashions for breasts in the generations in the developed world.

But deep inside, the breast to an African woman is much more than a sexual organ. In Africa it is the life bringing organ that allows a child to survive above 1 year of age. To the woman it makes her attractive to her man. To the man it is sexual and brings the relationship between his wife and his mother into stark reality.

But the breast is attached to a woman. A woman with feelings and, in Africa, a need to survive in the world of men. Losing a breast may make her unacceptable to her husband. She may be sent back to her family without her children. And the age for onset of breast cancer is much younger than in the developed world.

So, breast cancer in Africa is a huge tragedy. In women it also sometimes occurs during pregnancy, and if the woman is among the $5 \%$ who are lucky enough to reach treatment, then they can only have it in the last trimester, when it may be too late (Fig. 1).

\section{Uganda}

In 1993, Uganda was chosen by Hospice Africa as the country in which to place a model hospice, Hospice Africa would reach out to all Africa at a time when only 3

*Correspondence: anne@hospiceafrica.or.ug

Hospice Africa Uganda, PO Box 7757, Kampala, Uganda of the 56 countries in Africa had any palliative care. Even today, many in the west still remember the atrocities carried out during the Amin and Obote eras in Uganda's history. But since 1986, Uganda has developed and grown under the leadership of President Yoweri Museveni. Since 1993, the population has grown from 23 million to 33 million and the prevalence of HIV has been reduced from $30 \%$ to $6.7 \%$ of the population. HIV has affected the incidence and prevalence of cancer. Today, $50 \%$ of cancer patients at Hospice Africa Uganda are HIV-positive. Although cancer of the breast is not directly linked with $\mathrm{HIV}$, the rates of all cancers have doubled with the advent of HIV.

Although it is difficult to get statistics in most African countries for any disease, Uganda has boasted a cancer registry for many years and Hospice Africa Uganda keeps its own statistics. Based in Kampala, the cancer registry is confined to one district, Kyandondo, and only records those who reach hospital and have a confirmed biopsy. Given that $57 \%$ of a population never see a health worker and $30 \%$ live on less than $\$ 2$ per day, it is apparent that not only are most cancer cases not recorded but they also never reach any form of health care, so the cancers grow and patients die in severe pain and displaying obvious symptoms witnessed by their grieving families.

\section{The findings at Hospice Africa Uganda}

Hospice Africa Uganda was founded in Kampala in 1993, but in 1998 was extended to two further districts, Mbarara in the south-west and the site of the second medical school and Hoima in the north-west, which was chosen because it was a deprived area with regard to infrastructure and services. The annual statistics collected cover these three hospice sites.

Cancer of the breast is the second most common cancer in women and the fourth among all cancers (both sexes), and more than 200 cases were cared for by Hospice Africa Uganda from 2009 to 2010 [1]. The age distribution of breast cancer shows the age of highest incidence to be younger than in western countries (Figure 2), occurring among women still looking after young families. This brings further tragedy and anxiety to them and their families in their last days. 


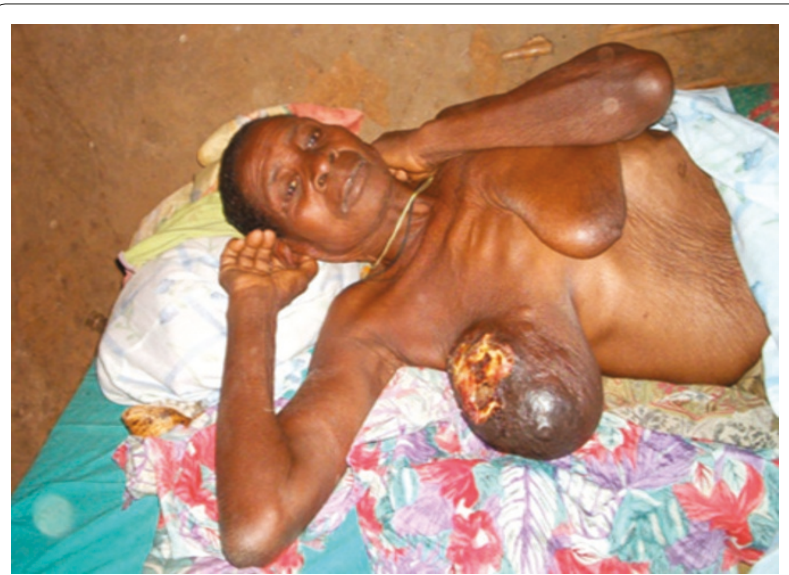

Figure 1. Mary, found like this in her home in a village by a community volunteer, received palliative care. Photograph courtesy of Dr Carla Simmons.

Pain, symptoms and psychosocial, cultural and spiritual issues are of prime importance in caring for these women. Pain must be relieved before the other paradigms can be considered and addressed. Pain may be due to direct spread or metastases and includes tissue pain, wound pain, and lymphoedema. Metastases can cause bone pain, pathological fractures, neuropathic pain, and raised intracranial pressure from brain metastases.

Before the advent of Hospice Africa Uganda, there were no medications for severe pain in Uganda. Oral morphine was a prerequisite to the commencement of palliative care in Uganda and this was embraced by the Ministry of Health, which has been supportive of this ever since, making palliative care an essential clinical service for all Ugandans in the Strategic Health care plan since 2000, and increasing the prescribers in a country where there is only 1 doctor to 19,000 people, so that nurses trained for 9 months at Hospice Africa Uganda are recognised and registered prescribers of morphine in the palliative care setting.

Morphine [2] is made up on site using imported powder, water, a preservative and cake colouring to denote the strengths. The standard strengths are $5 \mathrm{mg}$, $50 \mathrm{mg}$ and $100 \mathrm{mg}$ per $5 \mathrm{ml}$. The cost of 10 days of pain relief for the average patient taking $30 \mathrm{mg}$ per day is the cost of a loaf of bread, and palliative care is now available in 13 of the 56 African countries. But working with the government to get it initially imported is only the start of the process. Making it available throughout each country has been a great challenge. For example, cancer of the breast is the commonest cancer in Nigeria, the most populated country in Africa, yet there are still only four outlets making oral morphine. Nigeria has a population of 150 million and an estimated 600,000 people requiring pain control for cancer at this time.

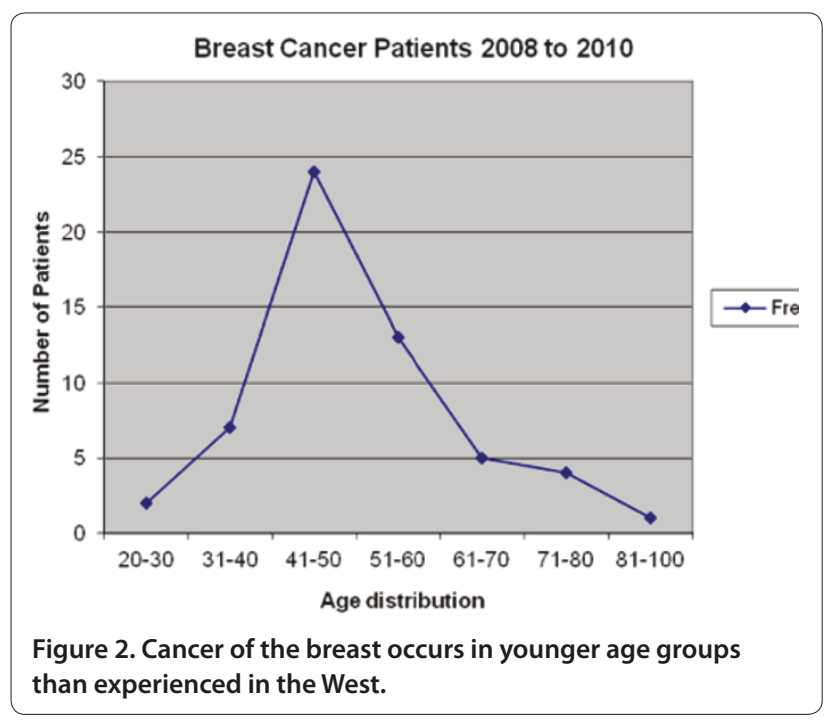

\section{Supporting patients where there is no oncology service}

Breast surgery may be available to those who can reach a hospital. However, less than $5 \%$ do so because of poverty, fear of returning in a box - having witnessed relatives returning from hospitals like this - and lack of trust in western medicine. Many will not report to any health worker, traditional or western, until too late. However, the traditional healer is cheaper and much more available Uganda has 1 traditional healer to 450 people. They also approach patients in a holistic manner, give them more time and relate their illness to their situation in life, which is culturally more acceptable than the approach of western medicine. Most have attended a traditional healer for some time before eventually presenting at the hospital. Thus, the possibility of a cure or even palliation from chemotherapy or radiotherapy is almost nil unless there is enough money in the family to send the patients abroad. A third of African countries have no oncology services.

\section{Managing patients at Hospice Africa Uganda Pain}

For somatic pain, we use the World Health Organization (WHO) analgesic ladder and this is affordable. For neuropathic pain not responding to morphine alone, we use amitryptiline and/or phenytoin; both these are cheap and available (for depression and epilepsy). For bone pain we use the step one analgesic (NSAID) combined with morphine, and maintain constant vigilance for paraplegia and pathological fractures. Lymphoedema is commonly due to very advanced disease with unrestrained growth, occasionally associated with radiotherapy. This can be painful and unsightly and we use massage from the distal part of the limb, showing relatives how to carry it out 
daily. Support bandaging is very hot and uncomfortable in this climate and the flotron too expensive.

\section{Symptoms}

Smelly and bleeding wounds are common de novo but also associated with the lancing of the tumour in mistake for an abscess. The smell is that of a dead body and isolates the woman from the family. It is due to anaerobic bacteria and is controlled very rapidly by sprinkling powdered metronidazole tablets over the wound two or three times a day. This also controls oozing of blood from the wound. Severe bleeding requires radiotherapy if it is available; if it is not, then the wound is bound firmly until the bleeding stops.

\section{Psychosocial, cultural and spiritual issues}

Sex and sexuality encompass not only the body image for the woman but the approach of her sexual partner to her changing image. Some wives are abandoned, others suffer brutal sexual advances while weak and in pain. Others find the man is unwilling to pay for her treatment as he is saving up to buy another wife when she dies. We are sometimes surprised to find a caring husband who will support her to the end.

Cultural issue that affect the woman are loss of reproductive function and an inability to bear more children. Relatives often think the cancer is a punishment for offending the ancestors, it is ju ju (witchcraft from an enemy), or that it is infectious, thus isolating her.

Spiritual issues can be a problem. Guilty feelings over past misdemeanours and the possibility of a vengeful God may separate a woman from her loving God. We give time to listening and praying with her whenever possible, in a way appropriate to her beliefs.

\section{How is Hospice Africa Uganda making a difference?} Hospice Africa Uganda does not have inpatients. Our patients walk in if they can but the majority are too sick and are visited at home or in the local hospital if admitted. Our initial referrals were mainly from hospitals but today, with community volunteers identifying cases in the villages and instructing on early identification, more and more are self referrals or through the community volunteer in the village. Within Uganda each hospice has an outreach, roadside clinics and day care at the hospice and outside sites, often in a church.

Cancer of the breast is always a tragedy but particularly in Africa today. Prevention and early identification are difficult. Women are instructed in checking for breast lumps through the clinics and community volunteers. There is now a mobile mammography machine attached to the only cancer centre in the country. This is free but relies on electricity being available in the village. Mammography machines are also available in private hospitals but only the wealthy can afford to take advantage of these.

To date, Hospice Africa Uganda has cared for more than 16,000 patients. We estimate that through those we train another 16,000 are being cared for; we train people from Uganda and other African countries up to degree level in palliative care. But there is a long way to go.

The WHO said in 1986 [3] that it would be generations before the developing world would have access to the oncology services that are available in the western world. Palliative care is affordable and can bring peace to those afflicted but we are short of funding for this work.

Yes, there are great challenges for research in breast cancer but what about the challenge of relieving suffering? 'Statistics are human beings with the tears wiped away' said Peter Selwyn [4]. In palliative care we deal with human beings and their tears.

\section{Abbreviations}

WHO, World Health Organization.

Competing interests

The author declares that she has no competing interests.

\section{Acknowledgements}

This article has been published as part of Breast Cancer Research Volume 12 Supplement 4, 2010: Controversies in Breast Cancer 2010. The full contents of the supplement are available online at http://breast-cancer-research.com/ supplements/12/S4

Published: 20 December 2010

\section{References}

1. Hospice Africa Uganda Annual Report 2009-10 [www.hospiceafrica.or.ug]

2. Merriman A, Harding R: Pain control in the African context: the Ugandan introduction of affordable morphine to relieve suffering at the end of life. Philos Ethics Humanit Med 2010, 5:10.

3. World Health Organization: Cancer Pain Relief. Geneva: World Health Organization; 1986

4. Selwyn P: Surviving the Fall: the Personal Journey of an AIDS Doctor. New Haven, CT: Yale University Press; 1998

doi:10.1186/bcr2740

Cite this article as: Merriman A: Emerging breast cancer epidemic: impact on palliative care. Breast Cancer Research 2010, 12(Suppl 4):S11. 